\title{
Efeito In Vitro do Extrato de Camellia Sinensis Sobre o DNA de Leucócitos Humanos
}

\author{
Daniele Scherer Drews ${ }^{1}$, Ivana Beatrice Manica da Cruz ${ }^{2}$, \\ Greice Franciele Feyh dos Santos Montagner ${ }^{3}$
}

\begin{abstract}
RESUMO
Bebidas à base de Camellia sinensis tem sido utilizadas por muitos séculos na medicina tradicional, sendo a infusão preparada com as suas foIhas. Um dos produtos à base de $C$. sinensis amplamente consumido é o chá verde, e seus benefícios vêm sendo associados a sua composição química. Por este motivo, o objetivo deste trabalho foi avaliar a possível atividade genotóxica do extrato de chá verde por meio da avaliação de danos no DNA pelo Teste Cometa. Desta forma, foi conduzido um ensaio in vitro a partir de leucócitos isolados de sangue periférico de indivíduos saudáveis. Os leucócitos isolados foram tratados com diferentes concentrações de extrato de $C$. sinensis, posteriormente sendo avaliado o dano no DNA pelo Teste Cometa. Os resultados encontrados neste trabalho indicaram que nas concentrações $3 \mu \mathrm{g} / \mathrm{mL}, 10 \mu \mathrm{g} / \mathrm{mL}, 30 \mu \mathrm{g} / \mathrm{mL}$, $100 \mu \mathrm{g} / \mathrm{mL}$ e $300 \mu \mathrm{g} / \mathrm{mL}$, o extrato de C. sinensis comportou-se igual ao controle, não apresentando diferença significativa no índice de danos do DNA, o que indica que nas concentrações utilizadas o extrato não apresentou efeito genotóxico. O uso do chá verde na dieta pode ter muitos benefícios para o organismo, principalmente pelos seus compostos bioativos e, por este motivo, fazem-se necessários estudos para avaliar sua toxicidade para melhor avaliar a segurança em seu uso.
\end{abstract}

Palavras-chave: Teste cometa. Chá verde. Genotoxicidade. Dano no DNA.

IN VITRO EFFECT OF CAMELLIA SINENSIS EXTRACT IN HUMAN DNA LEUKOCYTES

\section{ABSTRACT}

Beverages based on Camellia sinensis have been used for many centuries in traditional medicine, with the infusion being prepared with its leaves. One of the widely consumed products of $\boldsymbol{C}$. sinensis is green tea, its benefits being associated with its chemical composition. For this reason, the objective of this work was to evaluate the possible genotoxic activity of the green tea extract through the evaluation of DNA damage by the Comet Assay. In this way, an in vitro assay was performed from leukocytes isolated from peripheral blood of healthy subjects. The isolated leukocytes were treated with different concentrations of $C$. sinensis extract, after which the DNA damage was evaluated by the Comet Assay. The results obtained show that DNA damage index to differente concentratios to $C$. sinensis extract was similar to the control, with no significant difference, which show that at the concentrations used the extract had no present genotoxic effect. The use of green tea in the diet can have many benefits for the organism, mainly for its bioactive compounds, therefore, studies are necessary to evaluate its toxicity, to better evaluate the safety in its use.

Keywords: Comet assay. Green tea. Genotoxicity. DNA damage.

RECEBIDO EM: $11 / 8 / 2019$

MODIFICAÇÕES SOLICITADAS EM: 7/11/2019

ACEITO EM: 10/7/2020

\footnotetext{
${ }^{1}$ Universidade Regional do Noroeste do Estado do Rio Grande do Sul - Unijuí. ljuí/RS, Brasil.

2 Universidade Federal de Santa Maria - UFSM. Santa Maria/RS, Brasil.

${ }^{3}$ Autora correspondente. Universidade Regional do Noroeste do Estado do Rio Grande do Sul - Unijuí. Rua do Comércio, 3000 - Bairro universitário. ljuí/RS, Brasil. http://lattes.cnpq.br/3492211662498366. https://orcid.org/0000-0001-8765-1452. greice.fdsantos@unijui.edu.br
} 


\section{INTRODUÇÃO}

Plantas medicinais têm sido amplamente utilizadas pela população, justamente pelo fato de seus consumidores acreditarem que seu uso, por serem naturais, é inerentemente seguro. Este aumento do uso estaria embasado no apelo de que não haveria contraindicações, por se tratar de produtos naturais (AKRAM et al., 2014). Desta forma, a análise química detalhada de plantas medicinais é necessária para que sejam destinadas ao uso terapêutico de forma segura, pois existem vários fatores que podem levar a variações no conteúdo de metabolitos secundários (GOBBO-NETO; LOPES, 2007) e suas interações com o organismo.

Os compostos bioativos, ingeridos tanto pelo uso de plantas medicinais quanto pelos compostos presentes na dieta, desempenham um papel crucial em processos fisiológicos e no status de saúde dos indivíduos. Tal ingestão pode ter um impacto tanto positivo quanto negativo sobre a interação destas moléculas com o metabolismo. Neste contexto, muitas plantas têm sido estudadas para avaliar seus efeitos sobre o organismo humano. Dentro disso, podemos destacar as espécies de família Theaceae, em especial a $\mathrm{Ca}$ mellia. sinensis, popularmente conhecida como chá verde (SENGER; SCHWANKE; GOTTLIEB, 2010; SIMÕES et al., 2004; MANFREDINI; MARTINS; BENFATO, 2004).

Camellia sinensis é um arbusto de pequeno porte, de origem da Ásia continental e da Indonésia, pertencente à família Theaceae (Figura 1). É um arbusto perenifólio grande ou arvoreta de 3-4 m de altura, de copa piramidal e densa. Apresenta folhas simples, elípticas, coriáceas, quase glabras, de $4-7 \mathrm{~cm}$ de comprimento; as flores são de cor branca, solitárias ou em grupo de duas ou três nas axilas foliares. Os frutos são cápsulas deiscentes e oblongas com 1-3 sementes. É cultivada principalmente na China, Índia, Sri Lanka, Japão, Quênia e Indonésia (SIMÕES et al., 2004; LORENZI; MATOS, 2008).

Figura 1 - Arbusto de Camellia sinensis

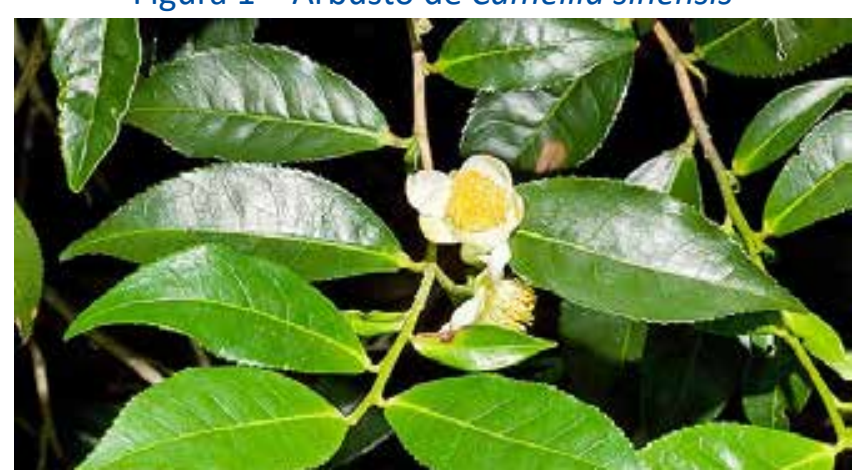

Fonte: http://www.photomazza.com/?Camellia-sinensis\&lang=en. Acesso em: 15 jan. 2019.
As folhas e botões de $C$. sinensis têm sido utilizados popularmente, principalmente na forma de chá. Os principais tipos de chás obtidos a partir desta planta são o chá verde, o chá oolong, o chá preto e o chá branco. As folhas jovens e brotos foliares são apresentados comercialmente como chá verde, este é produzido por dessecação das folhas sem fermentação, o chá oolong sofre fermentação parcial apenas e o chá preto é produzido por dessecação após fermentação (LORENZI; MATOS, 2008).

As propriedades farmacológicas da $C$. sinensis estão relacionadas à presença de compostos bioativos. As folhas não fermentadas contêm proteínas (15\% a $20 \%$ ), glicídeos (5\%), ácido ascórbico, vitaminas do complexo $B$ e bases púricas, especialmente a cafeína ( $2 \%$ a $4 \%$ ), polifenóis (30\%): monosídeos de flavonóis e flavonas, catecóis e epicatecóis livres e esterificados pelo ácido gálico e produtos de condensação, taninos (10 a 24\%) (PRADO et al., 2005; SILVA; SILVA; MICHELIN, 2013; PINTO et al., 2015; PEREIRA et al., 2009).

Pesquisas revelam seu efeito benéfico em algumas patologias e, por tratar-se de uma bebida amplamente disponível e de baixo custo, seu uso torna-se viável como um importante coadjuvante em diversas patologias (SENGER; SCHWANKE; GOTTLIEB, 2010; CAVALCANTI et al., 2007; SUZUKI-SUGIHARA et al., 2016; PRASAD; KATIYAR, 2015). A dose diária recomendada de chá verde ainda é estudada, pois não há consenso da quantidade e frequência do uso do chá. Na literatura, entretanto, há indícios de que para alcançar benefícios à saúde a ingestão diária seja de 5 a 7 xícaras de chá/dia (WEISBURGER, 1999; SENGER; SCHWANKE; GOTTLIEB, 2010).

Dentre os compostos bioativos presentes no chá verde, as catequinas são as que estão em maior quantidade e possuem várias atividades biológicas, como antioxidante, antiangiogênica, antiproliferação do câncer e tem sido relevantes para a prevenção do câncer. (CAVALCANTI et al., 2007; COOPER; MORRÉ; MORRÉ, 2005; THIELECKE; BOSCHMANN, 2009).

Apesar do potencial uso farmacológico da C. sinensis, estudos sobre as suas propriedades funcionais e toxicológicas ainda estão sendo realizados. Por este motivo, o objetivo deste estudo é avaliar os possíveis danos no DNA de leucócitos de indivíduos saudáveis expostos ao extrato de $C$. sinensis, contribuindo, assim, para um uso mais seguro da $C$. sinensis. 


\section{METODOLOGIA}

\section{Delineamento}

O estudo foi realizado em uma única etapa, quando o sangue foi coletado de diferentes indivíduos por punção venosa e, logo após a coleta, os leucócitos foram separados. A separação de leucócitos foi realizada por centrifugação, e os leucócitos obtidos foram divididos em microtubos com igual suspenção celular $\left(10^{6} \mathrm{cels} / \mathrm{mL}\right)$ e mantidos em Hank's até o tratamento. A suspensão celular foi tratada com extrato de $C$. sinensis em concentrações finais de $3 \mu \mathrm{g} / \mathrm{mL}, 10 \mu \mathrm{g} / \mathrm{mL}$, $30 \mu \mathrm{g} / \mathrm{mL}, 100 \mu \mathrm{g} / \mathrm{mL}$ e $300 \mu \mathrm{g} / \mathrm{mL}$ por $1 \mathrm{~h}$ a $37 \mathrm{Co}$. Em seguida foram avaliados os danos no DNA pelo teste cometa.

\section{Preparo do extrato de Camellia sinensis}

$O$ extrato utilizado neste estudo foi previamente preparado deixando as folhas de $C$. sinensis em contato com água destilada ( $1 \mathrm{~g}$ de folhas $/ 100 \mathrm{~mL}$ de água) a $80^{\circ} \mathrm{C}$ por 15 minutos. Após, o extrato obtido foi rotaevaporado e liofilizado e armazenado a \pm 4 으 até o momento de uso. Para utilização nos testes in vitro o extrato foi diluído em água.

\section{Coleta, preparo da amostra e tratamento}

O sangue foi coletado de três indivíduos saudáveis por punção venosa, utilizando heparina sódica como anticoagulante. Os leucócitos foram obtidos por centrifugação e, posteriormente, lavados com solução lisante de hemácias. Para os testes in vitro, o pellet obtido foi ressuspendido em Hank's e a densidade celular determinada com o auxílio de câmara de Neubauer com corante Trypan blue 0,4\%.

A suspensão celular obtida foi dividida igualmente para os tratamentos, de modo que todos apresentaram $10^{6}$ células $/ \mathrm{mL}$ e mantida em Hank's. O extrato foi diluído em água na concentração de $1,5 \mathrm{mg} /$ $\mathrm{mL}$ e adicionado aos tratamentos de forma a obter concentrações finais de $3 \mu \mathrm{g} / \mathrm{mL}, 10 \mu \mathrm{g} / \mathrm{mL}, 30 \mu \mathrm{g} / \mathrm{mL}$, $100 \mu \mathrm{g} / \mathrm{mL}$ e $300 \mu \mathrm{g} / \mathrm{mL}$ em um volume de $250 \mu \mathrm{L}$; para o controle foi adicionado solução de Hank's apenas. Após preparo, os tratamentos foram mantidos a $370 \mathrm{C}$ por $1 \mathrm{~h}$ e, em seguida, realizado o teste cometa. Todas as análises foram realizadas em duplicata.

\section{Avaliação do dano no DNA pelo Ensaio do Cometa}

Para a avaliação de danos no DNA foi utilizado o teste Cometa, que segue o protocolo de deteç̧ão de danos em células eucarióticas em condições alcalinas, elaborado por Singh et al. (1988). Após a realização dos tratamentos, a suspensão celular foi misturada com agarose de baixo ponto de fusão, e em lâminas de microscopia pré-cobertas com agarose de alto ponto de fusão. As lâminas foram mantidas em solução de lise por pelo menos 1 hora, após foram submetidas ao tratamento alcalino (20 minutos) e, em seguida, submetidas à eletroforese (25V, $300 \mathrm{~mA}$ por 20 minutos). Logo após foi realizada a neutralização, fixação e coloração das lâminas com solução à base de nitrato de prata.

As lâminas foram analisadas com o auxílio do microscópio óptico (50 células/lâmina), em que cada célula foi analisada individualmente e o dano classificado visualmente de zero a quatro, e a extensão da migração do DNA foi relacionada com o dano ocorrido (TICE et al., 2000 ); posteriormente, foi calculado o índice de danos multiplicando o número de células pela classe do dano, obtendo-se, assim, um índice de danos de zero-200.

\section{Análise estatística}

Os dados foram plotados em planilha eletrônica Excel e, posteriormente, transferidos e analisados pelo programa estatístico SPSS versão 12.0. As variáveis quantitativas foram analisadas pelos testes Student $t$ para a comparação dos tratamentos com extrato nas diferentes concentrações, com o controle e a análise de variância One-way para comparação entre os grupos. Foram consideradas significativas as comparações com $\mathrm{P}<0,05$.

\section{Aspectos éticos}

O estudo está registrado sob o número 56972216.5.0000.5350, e foi aprovado pelo Comitê de Ética em Pesquisa (Unijuí) sob parecer número 1.692.526.

\section{RESULTADOS E DISCUSSÃO}

A C. sinensis é uma planta conhecida em todo o mundo e também muito utilizada na medicina tradicional, sendo a forma mais ingerida a do chá verde. Com a descoberta de diversos compostos bioativos presentes na planta, o uso se tornou ainda maior. Neste estudo foi avaliado o efeito do extrato de $C$. sinensis no dano ao DNA de leucócitos utilizando o teste cometa. Foi observado que nas concentrações de $3 \mu \mathrm{g} /$ $\mathrm{mL}, 10 \mu \mathrm{g} / \mathrm{mL}, 30 \mu \mathrm{g} / \mathrm{mL}, 100 \mu \mathrm{g} / \mathrm{mL}$ e $300 \mu \mathrm{g} / \mathrm{mL}$ o extrato de $C$. sinensis comportou-se igual ao controle (Figura 2), não apresentando diferença significativa no 
índice de danos do DNA, o que pode indicar que nas concentrações utilizadas o extrato não apresenta efeito genotóxico.

\section{Figura 2 - Avaliação do efeito genotóxico in vitro} do extrato de Camellia sinensis (em leucócitos humanos $(\mathrm{n}=3$ ), teste student $t$ (comparação com o controle) e análise de variância One Way (comparação entre os grupos)

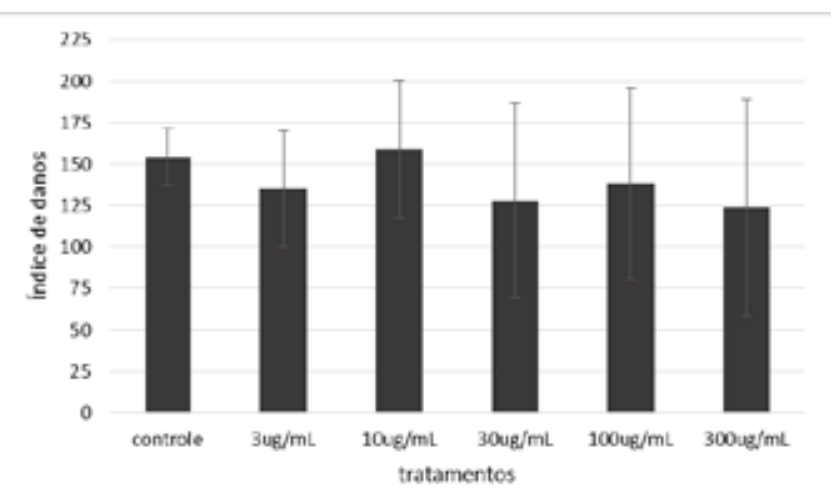

Fonte: Dados dos autores.

Na literatura já é bem descrito que o chá verde é rico em flavonoides, que apresenta em sua composição diversos compostos como cafeína, catequina, epicatequina e epigalocatequina galato, e também é descrito que este apresenta atividade antioxidante (NISHIYAMA et al., 2010). Diante disso, neste estudo optou-se por utilizar o extrato aquoso obtido por infusão, mimetizando as condições de uso comum, e, por este motivo, também optou-se por utilizar o extrato bruto e não os componentes isolados. Ainda com base na literatura, foi optado por utilizar o extrato em diferentes concentrações, observando, assim, se em altas concentrações este poderia apresentar efeito genotóxico (CABRERA, 2006).

$\mathrm{O}$ Ensaio do Cometa consiste em um método sensível para detectar danos no DNA, os quais acontecem por meio da quebra da cadeia de DNA. Este ensaio tem sido utilizado amplamente em diversos modelos experimentais, incluídos testes in vitro, ou em estudos de monitoramento em humanos para avaliar danos decorrentes de exposição à pró-oxidantes, geralmente associados ao estresse oxidativo (COLLINS, 2014; VENTURA et al., 2013).

A instalação do estresse oxidativo se dá por meio de um desequilíbrio entre os fatores pró-oxidantes e antioxidantes, sendo os fatores pró-oxidantes relacionados principalmente às exposições ambientais e hábitos de vida. Já o sistema de defesa antioxidante tem por objetivo manter o processo oxidativo dentro dos limites fisiológicos e passiveis de regulação, impedindo ou reduzindo danos causados pela ação deletéria de espécies reativas geradas pelo metabolismo
(BARBOSA et al., 2010). Diante disso, a dieta, é sem dúvida, um fator de grande importância na modulação do estresse oxidativo, dada a importância de antioxidantes presentes em sua composição.

A ingestão regular de chá verde associa um menor dano ao DNA e uma maior resistência do mesmo a efeitos antioxidantes, sendo relatados estes efeitos em estudos in vitro. No estudo de Ho et al. (2014), linfócitos periféricos de voluntários saudáveis foram incubados em soluções de chá recém-preparadas por 30 minutos a 37 으. Os efeitos genoprotetores do chá verde foram avaliados por meio do ensaio do cometa e observou-se que baixas doses de chá verde poderiam estar relacionadas à proteção antioxidante direta, decorrente dos polifenóis presentes em sua composição. Estudos in vitro com leucócitos humanos ainda não foram realizados para observar o efeito genotóxico do extrato de $C$. sinensis, sendo este o único estudo com um modelo parecido ao utilizado, o qual mostra que o chá verde tem proteção antioxidante na célula e o mesmo se dá pelos seus compostos bioativos.

No estudo realizado por Magcwebeba et al. (2016) foram avaliadas as propriedades quimiopreventivas do chá verde, utilizando-se um modelo in vivo na pele do rato. $O$ objetivo foi determinar o efeito antiproliferativo e a atividade pró-apoptótica em diferentes células da pele, empregando o chá verde como referência. $A$ atividade metabólica na célula foi interrompida pela despolarização da membrana mitocondrial, e observou-se que a atividade antiproliferativa do extrato de chá verde foi mediada, principalmente, pelos flavonoides. Nas concentrações mais baixas a proliferação celular foi inibida, à medida que, a uma concentração mais elevada, foi observado aumento na apoptose, dirigindo-se, principalmente, à remoção de células pré-cancerosas.

Durgo et al. (2011) avaliou os potenciais efeitos citotóxicos e pró-oxidativos do extrato de chá verde em seus dois principais constituintes flavonoides: as epigalocatequina galato (EGCG) e galato de epicatequina (ECG) na linha celular de carcinoma de laringe humana (HEp2) e sua linhagem celular resistente CK2 (citoqueratina). O objetivo foi verificar se o extrato e seus dois flavonoides poderiam aumentar a sensibilidade da linhagem celular CK2 resistente à cisplatina em comparação com a linhagem celular parental. Extrato de chá verde e catequinas no extrato de chá verde causam efeitos antioxidantes e pró-oxidantes, dependendo do tipo de célula, tempo de exposição e concentração. De forma geral, foi observado que os compostos biologicamente ativos, presentes no extrato de chá verde, podem ter um efeito significativo so- 
bre células resistentes, sugerindo, então, que o consumo de chá verde pode ajudar na prevenção de câncer em razão de seu efeito inibitório sobre o crescimento das células da laringe.

Diversos estudos abordam os efeitos benéficos do chá verde, no entanto são escassos os que avaliam seus efeitos tóxicos, decorrentes do uso de altas doses do chá. Desta forma, estudos como este, que avaliam a genotoxicidade, são importantes para a segurança e o uso do chá verde em diversas terapias. Os resultados apresentados neste estudo indicam que o extrato, nas condições e concentrações estudadas, não apresentou efeito genotóxico.

\section{CONSIDERAÇÕES FINAIS}

Conhecer o efeito dos componentes químicos presentes nas plantas torna-se cada vez mais importante, e o uso das mesmas na dieta tem crescido. 0 uso de chás e extratos de plantas tem sido foco de estudos e, a partir dos efeitos que estes produzem, pode-se ter benefícios, com uma dose a ser tomada diariamente em concentrações certas. Diversos estudos in vitro vêm sendo feitos para provar este efeito não somente no organismo humano, mas, também, no DNA, avaliando sua toxicidade para melhor estabelecer a segurança para seu uso. Neste sentido, o presente trabalho demonstrou que o extrato de $C$. sinensis não apresentou efeito genotóxico in vitro em leucócitos humanos observado pelo Teste Cometa.

\section{AGRADECIMENTOS}

Ao Laboratório de Biogenômica da UFSM e ao Laboratório de Ensaios Biológicos da Unijuí.

\section{REFÊRENCIAS}

AKRAM, M.; HAMID, A.; KHALIU, A.; GHAFFAR, A.; TAYYABA, N.; SAEED; A. ALFA; M., NAVEED. Review on medicinal uses, pharmacological, phytochemistry and immunomodulatory. Activity of Plants International Journal of Immunopathology and Pharmacology, 27(3), p. 313-319, 2014.

BARBOSA, K. B. F.; COSTA, N. M. B.; ALFENAS, R. C. G.; DE PAULA, S. O.; MINIM, V. P. R.; BRESSAN, J. Estresse oxidativo: conceito, implicações e fatores modulatórios. Rev. Nutr., Campinas, 23(4), p. 629-643, 2010.

CABRERA, C.; ARTACHO, R.; GIMÉNEZ, R. Beneficial Effects of Green Tea - A Review. Journal of the American College of Nutrition, 25, p. 79-99, 2006.

CAVALCANTI, Á. S. S.; ROSA, J. A. B.; LIMA, M. S. C. S.; SILVA, A. G. O uso do chá verde, Camellia sinensis L. (Theaceae) em produtos tópicos - uma revisão. Natureza on-line, 5(2), p. 76-84, 2007.
COLLINS, A. R. Measuring oxidative damage to DNA and its repair with the comet assay. Biochimica et Biophysica Acta, 1.840, p. 794-800, 2014.

COOPER, R.; MORRÉ, D. J.; MORRÉ, D. M. Medicinal Benefits of Green Tea: Part I. Review of Noncancer Health Benefits. The Journal of Alternative and Complementary Medicine. 11(3), p. 521-528, 2005.

DURGO, K.; KOSTIĆ, S.; GRADIŠKI, K.; KOMES, D.; OSMAK, M.; FRANEKIĆ, J. Genotoxic effects of green tea extract on human laryngeal carcinoma cells in vitro. Arh Hig Rada Toksikol, 62, p. 139-146, 2011.

GOBBO-NETO, L.; LOPES, N. P. Plantas medicinais: fatores de influência no conteúdo de metabolitos secundários. Quim. Nova, 30(2), p. 374-381, 2007.

HO, C. K.; CHOI, S. W.; SIU, P. M.; BENZIE, I. F. Effects of single dose and regular intake of green tea (Camellia sinensis) on DNA damage, DNA repair, and heme oxygenase-1 expression in a randomized controlled human supplementation study. Molecular Nutrition \& Food Research, 58(6), Version of Record on-line, 2014.

KITAGAWA, N.; MORIKAWA, T.; MOTAI, C.; NINOMIYA, K.; OKUGAWA, S.; NISHIDA, A.; YOSHIKAWA, M.; MURAOKA, O. The Antiproliferative Effect of Chakasaponins I and II, Floratheasaponin A, and Epigallocatechin 3-O-Gallate Isolated from Camellia sinensis on Human Digestive Tract Carcinoma Cell Lines. Int. J. Mol. Sci., 17, p. 1.979, 2016.

LORENZI, H.; MATOS, F. J. A. Plantas medicinais no Brasil: nativas e exóticas. 2. ed. Nova Odessa, SP: Instituto Plantarum, 2008. 544 p.

MAGCWEBEBA, T. U.; SWART, P.; SWANEVELDER, S.; JOUBERT, E.; GELDERBLOM, W. C. A. In Vitro Chemopreventive Properties of Green Tea, Rooibos and Honeybush Extracts in Skin Cells. Molecules, 21, p. 1.622, 2016.

MANFREDINI, V.; MARTINS, V.D.; BENFATO, M. da S. Chá verde: benefícios para a saúde humana. Infarma, 16, p. 9-10, 2004.

NISHIYAMA, M. C.; COSTA, M. A. F.; da COSTA, A. M.; SOUZA, C. G. M.; BÔER, C. G.; BRACHT, C. K.; PERALTA, R. M. Chá verde brasileiro (Camellia sinensis var assamica): efeitos do tempo de infusão, acondicionamento da erva e forma de preparo sobre a eficiência de extração dos bioativos e sobre a estabilidade da bebida. Ciênc. Tecnol. Aliment., 30(1), p. 191-196, 2010.

PRADO, C. C.; ALENCAR, R. G.; PAULA, J. R.; BARA, M. T. F. Avaliação do teor de polifenóis da Camellia sinensis (chá verde). Revista Eletrônica de Farmácia, 2, p. 164-167, 2005.

PRASAD, R.; KATIYAR, S. K. Polyphenols from green tea inhibit the growth of melanoma cells through inhibition of class I histone deacetylases and induction of DNA damage. Genes \& Cancer, 6, p. 1-2, 2015.

PEREIRA, A. V.; ALMEIDA, T. C.; BELTRAME, F. L.; COSTA, M. E.; GARRIDO, L. H. Determinação de compostos fenólicos em amostras comerciais de chás verde e preto - Camellia sinensis (L.) Kuntze, Theaceae, Maringá, 31(2), p. 119-124, 2009. 
PINTO, N. B. P.; ALEXANDRE, B. da S.; NEVES, K. R. T.; SILVA, A. H.; LEAL, L. K. A. M.; VIANA, G. S. B. Neuroprotective Properties of the Standardized Extract from Camellia sinensis (Green Tea) and Its Main Bioactive Components, Epicatechin and Epigallocatechin Gallate, in the 6-OHDA Model of Parkinson's Disease. Hindawi Publishing Corporation Evidence-Based Complementary and Alternative Medicine. Article ID 161092, 12 p. Vol. 2015.

SAIGG, N. L.; SILVA, M. C. Efeitos da utilização do chá verde na saúde humana. Universitas: Ciências da Saúde, Brasília, 7(1), p. 69-89, 2009.

SENGER, A. E. V.; SCHWANKE, C. H. A.; GOTTLIEB, M. G. V. Chá verde (Camellia sinensis) e suas propriedades funcionais nas doenças crônicas não transmissíveis. Scientia Medica, Porto Alegre, 20(4), p. 292-300, 2010.

SILVA, B. C.; SILVA, F.; MICHELIN, D. C. Avaliação da qualidade de amostras de Camellia sinensis (L.) Kuntze (Theaceae) comercializadas no município de Araras - SP. Rev. Ciênc. Farm. Básica Apl., São Paulo, 34(2), p. 245-250, 2013.

SIMÕES, C. M. O.; SCHENKEL, E. P.; GOSMANN, G.; MELLO, J. C. P.; MENTZ, L. A.; PETROVICK, P. R. Farmacognosia, da Planta ao Medicamento. 5. ed. Porto Alegre: Editora da UFRGS; Florianópolis: Editora da UFSC, 2004.

SINGH, N. P. et al. A simple technique for quantitation of low levels of DNA damage in individual cells. Exp Cell Res, 175(1), p. 184-191. DOI: 10.1016/0014-4827(88)90265-0. PMID: 3345800.

SUZUKI-SUGIHARA, N.; KISHIMOTO, Y.; SAITA, E.; TAGUCHI, C.; KOBAYASHI, M.; ICHITANI, M.; UKAWA, Y.; SAGESAKA, Y.M.; SUZUKI, E.; KONDO, K. Green tea catechins prevent low-density lipoprotein oxidation via their accumulation in low-density lipoprotein particles in humans. Nutrition Research, 36(16), p. 23, 2016.

THIELECKE, F.; BOSCHMANN, M. The potential role of green tea catechins in the prevention of the metabolic syndrome - A review. Phytochemistry, 70, p. 11-24, 2009.

TTICE, R. R. et al. Single Cell Gel/Comet Assay: Guidelines for In Vitro and In Vivo Genetic Toxicology Testing. Environmental and Molecular Mutagenesis, 35(3), p. 206-221, 2000. DOI: 10.1002/(sici)1098-2280(2000)35:3<206::aid-em8>3.0.co;2-j. PMID: 10737956.

VENTURA, L.; GIOVANNINI, A.; SAVIO, M.; DONÀ, M.; MACOVEI, A.; BUTTAFAVA, A.; CARBONERA, D.; BALESTRAZZI, A. Single Cell Gel Electrophoresis (Comet) assay with plants: Research on DNA repair and ecogenotoxicity testing. L. Chemosphere, 92, p. 1-9, 2013.

WEISBURGER J. H. Tea and health: the underlying mechanisms. Proc Soc Exp Biol Med., 220, p. 271-275, 1999. 